\title{
NOTAS MICOLOGICAS VI. \\ Pleurophomopsis lignicola Y Cladophialophora bantiana DOS NUEVOS AGENTES DE MICOSIS OPORTUNISTAS EN CHILE
}

\author{
(Mycological notes VI. Pleurophomopsis lignicola and Cladophialophora \\ bantiana two new agents of opportunistic mycoses in Chile)
}

\author{
*María Cristina Díaz, J., **Eduardo Piontelli, L. \\ ***Pabla Martínez, O. \& ****Marcela Cifuentes. \\ Universidad de Chile, Facultad de Medicina,ICBM, Programa \\ de Microbiología y Micología, Independencia 1027, Santiago,Chile \\ **Universidad de Valparaíso, Escuela de Medicina, \\ Cátedra de Micología, Casilla 92 V, Valparaíso. \\ *** Hospital Clínico Universidad de Chile, \\ Unidad de Microbiología, Lab. Central, Santos Dumont 999.Santiago \\ **** Hospital Clínico San Borja Arriarán, Servicio \\ de Microbiología, Av.Santa Rosa 1234, Santiago.
}

Palabras claves: Micosis oportunistas, Pleurophomopsis lignicola, Cladophialophora bantiana Key words:Opportunistics mycoses, Pleurophomopsis lignicola, Cladophialophora bantiana

\section{RESUMEN}

Se comentan los aspectos ecológicos, morfológicos y taxonómicos de 2 interesantes agentes etiológicos de micosis oportunistas no descritos en el país. El primero, un paciente de sexo masculino de 50 años, con lupus eritematoso diseminado y multiples infecciones bacterianas, donde desde un absceso cutáneo del dedo indice se aisló repetidamente Pleurophomopsis lignicola. El segundo, un paciente de sexo masculino 68 años, agricultor con abscesos cerebrales múltiples donde se aisló el agente fúngico neurotrópico Cladophia-lophora bantiana.

\section{CASO I}

Datos clínicos .- Paciente de sexo masculino, 50 años, con lupus eritematoso diseminado, hipertensión arterial y múltiples infecciones bacterianas. Desde un absceso cutáneo del dedo índice izquierdo se aisló repetidamente en medio de cultivo, un hongo dematiaceo que se clasificó como Pleurophomopsis lignicola.

\section{Estudio micológico.}

Desde el aislamiento enviado en agar Sabouraud para su identificación se hicieron subcultivos en agar papa

\section{ABSTRACT}

The ecological, morphological and taxonomic aspect of two interesting etiological agents of opportunistic mycoses, which had never been described before in the country, are discussed. The first case, a 50-aged masculine patient suffering from disseminated erythematous lupus as well as from multiple bacterial infections whose index finger showed a cutaneous abscess and in wich Pleurophomopsis lignicola was isolated repeatedly. The second case, a 68-aged masculine farmer having multiple brain abscesses that made it possible to isolate the neurotropic fungal agent Cladophialophora bantiana.

dextrosa y agar malta. En los cultivos incubados a 27 y $37^{\circ} \mathrm{C}$ durante 14 días se desarrollaron colonias de color gris oliváceo de crecimiento lento $\left(2 \mathrm{~cm}\right.$ en 14 días a $\left.27^{\circ} \mathrm{C}\right)$, de aspecto algodonoso por el abundante micelio aéreo laxo y con un reverso de color oliva oscuro a negro. Al examen microscópico se observaron hifas dematiáceas a levemente hialinas ramificadas, lisas y rugosas, septadas, sin ninguna estructura conidiógena visible aún a los 30 días. Se hicieron subcultivos a $25^{\circ} \mathrm{C}$ en agar papa dextrosa, agar harina de maíz y en agar agua con hojas de clavel esterilizadas superficialmente con hipoclorito de sodio al 5\% duran- 
te 5 minutos. En los dos primeros medios se obtuvieron colonias del mismo aspecto que en Sabouraud, sin ninguna fructificación aparente salvo en un tubo con agar harina de maíz donde se desarrollaron solamente 2 picnidios semi inmersos, sin embargo, en agar agua con hojas de clavel se desarrolló un micelio bajo, de color café grisáceo con una buena cantidad de picnidios ostiolados subglobosos a pirifor-mes. Conidioma de paredes gruesas melanizadas en la parte externa recubierta de células café oscuras de textura angularis y células más hialinas en su interior, rodeado de hifas flexuosas oscuras, 180-210x 340-390 $\mu$ m. Conidióforos hialinos cilíndricos cortos con 1 o 2 septos y ramificados en su base, que nacen de las paredes internas del conidioma. Células conidiógenas densamente compactas, de aspecto filiforme a cilíndrico, que se adelgazan hacia el ápice, discretas, sobres las células que limitan la cavidad interna del conidioma o integradas al conidióforo, enteroblásticas, fialídicas, hialinas, lisas, con locus conidiógenos terminales o laterales (acropleuró-genos), sobre cortas ramas que nacen debajo del septo 10-16x 1,5 $\mu \mathrm{m}$. Conidios hialinos, lisos, elípticos a sub-globosos, de paredes delgadas, gutulados, aseptados 2,5-3 x 1,5-1,8 $\mu$ m, en masas mucoides que se proyectan fuera del ostíolo en un corto cirro de color blanquecino (Figuras 3 al 8). Tres cepas se mantienen en cultivo en el cepario EMV bajo el número 161.

Diagnóstico: Pleurophomopsis lignicola Petrak. Ann. Mycol. 22:1-182, 1924

Aspectos ecológicos y taxonómicos.- Los hongos mitospóricos incluidos en los Coelomycetes son aquellos que presentan conidios en picnidios, acérvulos y estromas (estructuras comúnmente llamadas conidio-mata). Integran la micota de ambientes relacionados con las plantas vasculares y sus diversos hábitat. Sus aspectos econutricionales, abarcan desde un comportamiento saprofítico, hasta el de débiles o agresivos parásitos, aún dentro de las especies de un determinado género, causando éstos últimos, graves problemas en el campo de la fitopatología. Algunos taxa son comunes en el suelo o en hábitat de agua dulce o salina, a veces son parásitos de otros hongos, pero su presencia es escasa en la micota anemófila. Como agentes de micosis oportunistas en el hombre, no se detectan con frecuencia, sin embargo, la literatura antigua y moderna menciona a algunos de sus representantes, en especial dentro del orden Sphaeropsidales (conidios en picnidios) y Melanconiales (conidios en acérvulos), implicados en cuadros clínicos diversos (Agostini \& Tredici 1937; Borelli, 1959,1976; Gentle \& Evans, 1970; Mariat et al., 1978; Padhye et al., 1997, Sutton, D. 1999). Punitha-lingam (1979), ilustra y presenta claves de las Sphaeropsidales en cultivo aisladas desde humanos, describiendo nuevas especies; Sutton, D. (1999), efectua una revisión del tema, mientras de Hoog et al.(2000), una clave útil actual de los Coelomycetes patógenos descritos en la literatura.

Los problemas en la delimitación en algunos grandes géneros de Coelomycetes, se mantienen aún con los progresos efectuados recientemente en las técnicas de cultivo, criterios morfológicos y bioquímicos, tales como: Phoma, Phomopsis, Colletotrichum, Coniothy-rium, Pyrenochaeta, u otros (Scneider, 1979; Sutton.B, 1980; Aa van der et al., 1990; Monte et al.,1990; Boerema, 1997). Si a esto sumamos el grado de variación experimentada por algunos géneros en cultivos y la dificultad de delimitar ciertos taxa de clasificación intermedia como los que presentan estroma, una conidio-génesis anelídica-fialídica difícil de apreciar o una sobreposición de características comunes en géneros similares, aumentan las dificultades para una correcta identificación para el micólogo médico (Sutton.D. 1999). Otros géneros presentan características tan similares entre si que su diferenciación morfológica es muy dificultosa y es necesario a veces la ayuda de expertos para una buena identificación, como en algunos integrantes del género Phoma, Pleurophoma, Pleurophomopsis, Microsphaeropsis, Coniothyrium, entre otros (Sutton.D, 1999). Sin embargo, algunos son menos complejos en su morfología y las características de sus mitosporas (conidios) son tan específicas que permiten una identificación menos problemática con el apoyo de monografías o textos especializados (Botryodiplodia theobromae, Colletotrichum, Natrassia mangifera, etc.).

Comentario general.- Este es el primer caso descrito en Chile que involucra a este Coelomycete en un absceso cutáneo. El paciente posiblemente adquirió el hongo por una lesión traumática penetrante que llevó hasta los tejidos subcutáneos algunas de sus estructuras o sus conidios desde el ambiente externo circundante, debido a que las 7 especies conocidas en la actualidad se han descrito desde material vegetal.

Los 3 casos anteriores donde se se ha reportado en la literatura internacional a P. lignicola como agente oportunista, son en un absceso subcutáneo (Chabasse et al.,1995), una sinusitis maxilar (Padhye et al., 1997) y en múltiples abscesos de tejidos blandos en un paciente con transplante de riñón (Farina et al., 1997). Todo los casos descritos corresponden al hemisferio norte y este correspondería al primer caso en el hemisferio sur.

Los Coelomycetes presentan grandes diversidades morfológicas y ontogénicas que cambian en dependencia al tiempo de cultivo o de ciertos factores ambientales y su conidiogénesis no puede aplicarse en términos absolutos (Minter et al., 1982). P.lignicola no esporula fácilmente en los medios de cultivos usados en micología médica y es necesario tratar de cultivarlo en agar avena (oat agar) bajo 

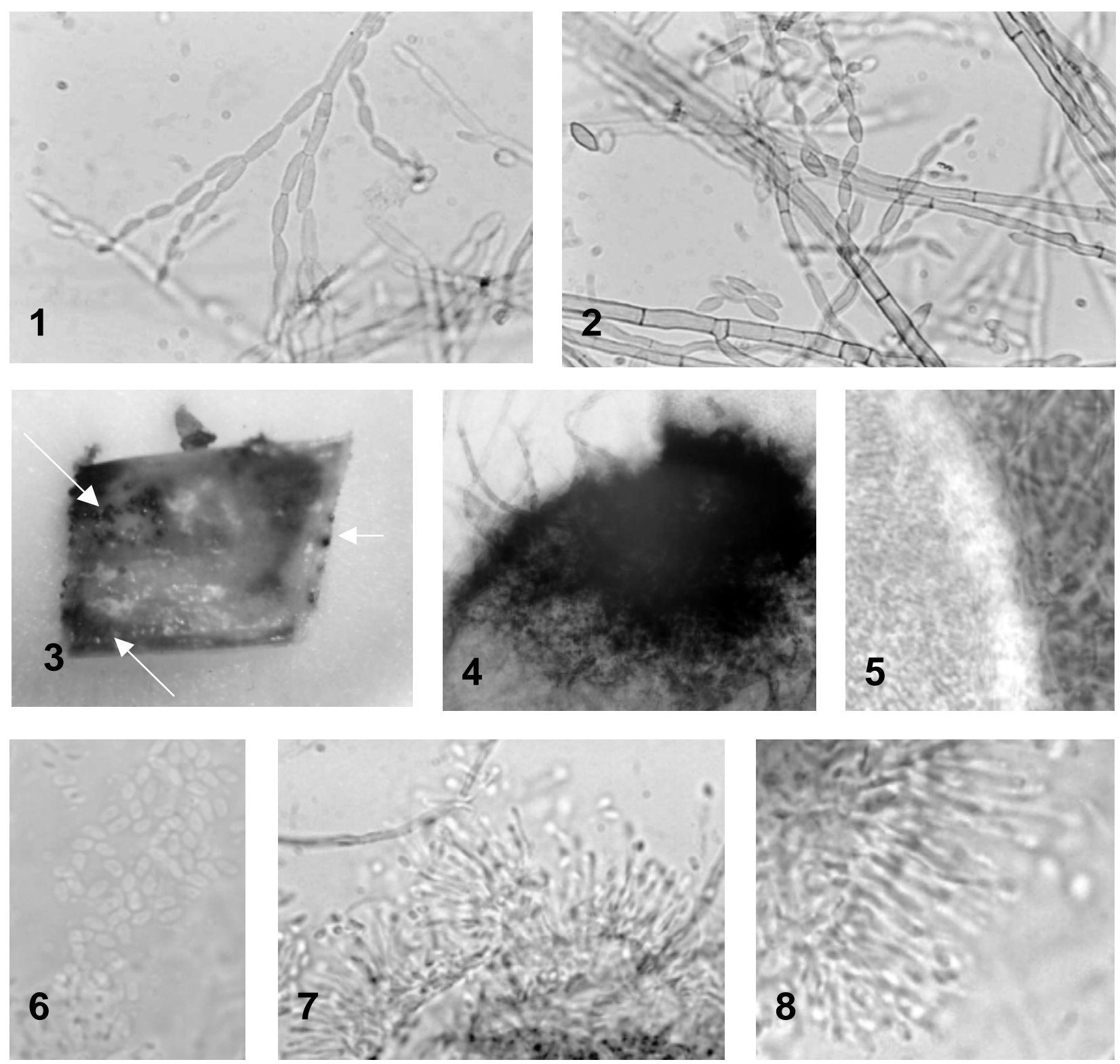

Figura 1. 1, 2.-Cladophialophora bantiana conidios fusiformes en largas cadenas poco ramificadas, 1000x. 3 a 8.- Pleurophomopsis lignicola. 3.- Picnidios semiinmersos (flechas) creciendo sobre un trozo de hoja de clavel en agar agua durante 12 días de incubación, 10x. 4.- Picnidio mostrando la zona del cuello y ostíolo, 200x. 5.- Grosor de las paredes del conidioma donde se aprecia la capa interna (zona clara) y externa (zona más oscura rodeada de hifas), 200x. 6.- Conidios elípticos, gutulados, de paredes delgadas, 1000x. 7-8.Parte interna de la pared delimitada con conidióforos densamente compactos a veces ramificados y septados en sus bases, células conidiógenas cilíndricas, hialinas (fialídicas) y conidios, 1000x.

un régimen mixto de $12 \mathrm{~h}$ luz negra (UV) y $12 \mathrm{~h}$ de oscuridad (International Mycological Institute, en Padhye et al., 1997 ) o en agar agua con trozos de hojas de clavel (carnation leaf agar) según lo propuesto por Sutton, D. (1999), para varios Coelomycetes, o en otros medios que contengan trozos de material vegetal esterilizado (Sutton, D., 1999) o simplemente en agar agua con un trozo de papel filtro como substrato.

\section{CASO II}

Datos clínicos .- Paciente de sexo masculino, 68 años, agricultor, que consulta por un cuadro de confusión mental. Por sospecha de metástasis cerebrales, fue intervenido extirpándose la mayoría de las lesiones, de las cuales se obtuvo material purulento para estudio microbiológico y 
cuyo estudio histológico demostró la presencia de hifas fúngicas dematiáceas.En los cultivos en Sabouraudon se desarrolaron multiples colonias de un hongo dematiáceo que se clasificó como Cladophia-lophora bantiana. Después de una terapia con vorico-nazol endovenoso falleció 10 días después del alta (Luppi et al.,2002).

\section{Estudio micológico.}

Colonias en PDA a $27^{\circ} \mathrm{C}$ de crecimiento lento de color oliváceo a negro, solevantadas en el centro, surcadas y de aspecto pulverulento en su superficie, reverso negro. Micelio café, septado con conidióforos indiferenciados o poco diferenciados de las hifas aéreas. Conidios abundantes, de formación acropétala, unice-lulares, de color café oliva claro, lisos dispuestos en largas cadenas poco ramificadas que se desarticulan fácilmente, elipsoidales, fusiformes a cilíndricos, sin cicatrices visibles de inserción, de paredes delgadas pero engrosándose en el tiempo, 510 x 2,5-4 $\mu \mathrm{m}$. Clami-dosporas y sinanamorfo en Phialophora ausentes. La cepa crece lentamente a $40^{\circ} \mathrm{C}$.

Tres cepas se mantienen en cultivo en el cepario EMV bajo el número 162.

Diagnóstico:Cladophialophora bantiana(Sacc.) de Hoog, Kwon-Chung \& McGinnis.(sensu lato) J. Med. Vet. Mycol. 1995; 33:343

\section{Sinónimos:}

三Torula bantiana Sacc. Ann. Mycol. 1912; 10:320

=Cladosporium bantianum (Sacc.) Borelli Riv. Anat. Patol. Oncol. 1960; 17:620

=Xylohypha bantiana (Sacc.) McGinnis, Padhye, Borelli \& Ajello J.Clin. Microbiol. 1986; 23:1150

=Xylohypha emmonsii (Sacc.) padhye, McGinnis \& Ajello

J.Clin. Microbiol. 1988; 26:704

=Cladosporium trichoides Emmons in Binford et al., Am.

J.Clin. Pathol. 1952; 22:535

=Cladosporium trichoides var. chlamidosporum KwonChung Mycologia 1983; 75:320

\section{Comentarios ecológicos, taxonómicos y}

moleculares. En las décadas recientes, los miembros de los géneros que poseen anamorfos semejantes a Cladosporium Link, han sido objeto de diversos estudios moleculares que han marcado una substancial división entre las cepas aisladas desde hospederos humanos o animales, las que mantienen una distancia filogenética mayor de la contraparte aislada desde el suelo u otros hábitat (Muller et al., 1987; Masclaux et al.1995; Haase et al.,1995; de Hoog et al., 1995; Untereiner,1997, Haase et al.,1999).

El género Cladoporium, se caracteriza por poseer conidios dematiáceos secos en cadenas ramificadas, con marcadas cicatrices oscuras de inserción. Es un taxon filogenéticamente heterogéneo porque posee varios teleomorfos incluidos en diferentes familias de Ascomycetes, en especial en la Mycosphaerellaceae (Dothideales), que incluye especies saprofíticas y fitopatógenas ampliamente dispersas en la naturaleza, como las especies cercanas a Cladosporium herbarum. Otros representantes considerados como semejantes a Cladosporium y capaces de causar micosis (cromoblasto-micosis) sistémicas en el hombre como Cladosporium carrionii Trejos (= Cladophialophora ajelloi Borelli) actualmente llamada Cladophialophora carrionii, se han relacionado recientemente mediante morfología y biología molecular a Capronia un género de ascomycete miembro de la familia Herpotrichiellaceae (Chaeto-thyriales), por sus semejanza al anamorfo de Capronia pilosella (Cladophialophora mansonii), pero también integrando parte de una rama monofilética constituida por un grupo de especies clasificadas en diversos taxa (incluyendo las llamadas levaduras negras) tales como: Cladosporium trichoides Emmons (=Xylohypha bantiana, actualmente Cladophialophora bantiana), Exophiala Carmichael, Fonsecaea Negroni, Phialo-phora Medlar, Ramichloridium, Stahel ex de Hoog y Toeniolella Hughes (de Hoog et al., 1995).

Cladosporium carrioni y las especies relacionadas, no presentan conidióforos diferenciados, tienen conidios pálidos sin cicatrices protuberantes, sus cadenas se desarticulan menos que las de $\boldsymbol{C}$. herbarum y sus relativos, son termotolerantes y no capaces de licuar la gelatina. Estas diferencias morfofisiológicas han permitido varios cambios en la nomenclatura de este grupo que ha sido estudiado y modificado por de Hoog et al.(1995). Estos autores transfieren C.carrioni y otros taxa patógenos humanos a Cladophialophora Borelli (Borelli,1980), un género que reune especies capaces de producir conidios en largas cadenas acropétalas como la producción de otros sinanamorfos semejantes a Phia-lophora.

Tres especies de Cladophialophora son agentes de micosis sistémicas en los humanos: C.arxii, C.devriesii y C.bantiana (De Hoog et al. 1995), la última especie es neurotrópica y causa infecciones cerebrales fatales principalmente en pacientes debilitados, considerándose en la actualidad entre los hongos más patogénicos conocidos. Su virulencia excede la de los Onygenales (Coccidioides e Histoplasma). Por su condición de poseer conidios secos fáciles de inhalar, se ha transferido recientemente a la categoría más alta de bioseguridad usada para los hongos (de Hoog, 1997).

Horre y de Hoog (1999), en una extensa revisión de las infecciones primarias cerebrales causadas por hongos dematiáceos, comentan que el problema principal relacionado con los hongos neurotrópicos y su principal 
agente causante Cladophialophora bantiana, se relaciona a que esta especie comprende en la actualidad varios taxa que han sido recientemente analizados por biología molecular (Gerris van der Ende \& de Hoog, 1999). C.bantiana ha sido aislada raramente de fuentes que excluyen los tejidos de los mamíferos y las cepas semejantes a $\boldsymbol{C}$. bantiana saprofíticas desde localiza-ciones que no sean de origen cerebral, parecen pertenecer a otros taxa, tales como Pseudocladosporium o Cladosporium (Braun, 1998; Padhey et al, 1999; Gerris van der Ende \& de Hoog, 1999). La mayoría de las cepas de C.bantiana son de distribución mundial (Europa, Africa, India, Japón, Australia, etc.), pero la mayoría se han obtenido del continente Americano. Los datos moleculares de la secuenciación de sus ITS de un gran set de cepas de la especie neurotrópica $\boldsymbol{C}$. bantiana sensu lato, indican un

\section{BIBLIOGRAFIA}

Boerema, G.H. (1997). Contribution towards a monograph of Phoma (Coelomycetes)-V. Subdivision of the genus in sections. Mycotaxon 64:321-333orelli, D. (1980). Causal agents of chromoblastomycosis (Chromomycetes). Proceeding of the Fifth Inter. Conference on the Mycoses..Sci.Publ.N³96 Pan American Health Organization. pp 334-335

Borelli, D. (1956). Pyrenochaeta romeroi n. Sp. Dermatología Venezolana 1:325-327

Borelli, D. (1976). Pyrenochaeta makinnonii nova specie agente de micetoma. Castellania 4:227-234

Braun, U. (1998). A monograph of Cercosporella, Ramularia and allis genera (Phytopathogenic Hyphomycetes) Vol. 2-IHW-Verlag, Mubich

Chabasse,D.; Bievre, C.de.; Legrand, E.; Saint-Andre,J.P. de Gentile,L.; Cimon, B.; Bouchara, J.P.(1995).Subcutaneous abscess caused by Pleurophomopsis lignicola Petrak: first case. J. Med \& Vet. Mycol. 33:415-417

Farina, C.; Punithalingham,E.; Ruggenenti, P.\& Goglio, A. (1997). Phaeohypho-mycotic soft tissue disease caused by Pleurophomopsis lignicola in a kidney transplant patient. J. Medical. Microbiology 46:699-703

Gentles, J.C. \& Evans, E.G.V. (1970). Infection of the feet and nails with Hendersonula toruloidea. Sabouraudia 8:72-75

Gerris van der Ende, A.H.G. \& de Hoog, G.S. (1999). Variability and molecular diagnostics of the neurotropic species Cladophialophora bantiana. Studies in mycology 43:151-162

Haase, G.L.; Sonntag, Y.; Melzer-Krick, B. \& de Hoog, G.S. (1999). Pylogenetic inference by SSU gene analysis of mem of the Herpotrichiellaceae, with special refernce to human pathogenic species. Stud.Mycol. 43:80-97

Haase, G.L.; Sonntag, Y.; van de Peer, J.M.J.; Uijthof, A.; Podbielski, A. \& aMelzer-Krick, B. (1995). Pylogenetic analysis of ten black yeast species using nuclear small subunit rRNA gene bajo grado de variabilidad. Las especies se restringen a cepas que difieren en menos de 6 posiciones de ITS1 y el grupo mayor de especies se forma alrededor de la cepa CBS173.52, la ex cepa tipo de Cladosporium trichoides. Los aislamientos de C. ban-tiana sensu stricto, consistentemente contiene un intron de 558 bp en la posición 1768, en el gen SSU rDNA, lo que ha sido determinado como estrictamente diagnóstico (Haase et al., 1999).

Aa, H.A. van der.; Noordeloos, M.E. \& Gruyter,J.de. (1990). Speciesconcepts in some larger genera of the Coelomycetes. Studies in Mycology 32:3-18

Agostini, A. \& Tredici, V. (1937). Sopra una nuova specie di micete commensale (Phoma hominis Agostini et Tredici) isolato da forme cliniche del derma. Atti dell'Istituto botanico e Laboratorio crittogamico della Reale Universitá di Pavia. Serv.iv, 9:179-189

sequence.Antonie van Leeuwenhoek 68:19-33

Hoog, G.S. de; Guého, E.; Masclaux, F.; Gerris van den Ende, A.H.G.; Kwon-Chung, K.J.; McGinnis, M.R. (1995). Nutritional physiology and taxonomy of human-patogenic CladosporiumXylohypha species. J. Med. Vet. Mycol. 33:339-347

Hoog, G.S.de.(1997).Risk assessment of fungi reported from humans and animals. Mycoses 39:407-417

Hoog, G.S. de; Guarro, J.; Gené, J. \& Figueras,M.J. (2000). Atlas of clinical fungi. $2^{\text {nd }}$. Ed. CBS/Universitat Rovira i Virgi

Horré, R. \& Hoog, G.S. de. (1999). Primary cerebral infections by melanized fungi:a review. Studies in Mycology 43:176-193

Luppi,M.;Diaz ,M.C.; Olivares, R.; Fica, A.; Saez, L.; Vasquez, P.; Baboor, M.(2002). Absceso cerebral letal por Cladophialophora bantiana. Experiencia terapéutica con Voriconazol. XIX Congreso Chileno de Infectología. 17-19 Nov, Santiago. Libro resúmenes, PO61. pp.65

Mariat, F.; Liautaud, B.; Liautaud, M. \& Marill, F.G. (1978). Hendersonula toruloidea, agent d'une dermatited verruqueuse mycosique observée en Algé rie. Sabouraudia 16:133-140

Masclaux, F.; Guého, E.; de Hoog,G.S. \& Christen, R.(1995)Phylogenetic relationships of human patogenic Cladosporium (Xylohypha) species inferred from partial LS rRNA sequences. J. Med. Vet. Mycol. 33:327-338

Minter, D.W.; Kirk, P.M. \& Sutton, B.C. (1982). Holoblastic fialides. Trans. Br. Mycol. Soc. 79:75-93

Monte, E.; Bridge, P.D. \& Sutton, B.C. (1990). Physiological and biochemical studies in Coelomycetes. Phoma. Studies in Mycology 32:21-28

Muller, E.; Petrini, O.;Fisher, P.J.; Samuels, G.J.;\& Rossman, A.Y. (1987). Taxonomy and anamorphs of the Herpotrichiellaceae with notes on generic synonymy. Trans. Br. Mycol.Soc. 88:63-74 
Padhye, A.A.; Gutekunst, R.W.; Smith, D.J. \& Punithalingam, E. (1997). Maxilary sinusitis caused by Pleurophomopsis lignicola. J. Clin. Microbiol. 35:2136-2141

Padhye, A.A.; Dunkel, J.D.; Winn, R.M.; Weber, S.; Ewing, E.P.. de Hoog, G.S. (1999). Subcutaneous phaeohyphomycosis caused by an undescribed Cladophialophora species. Sudies in Mycology.43:172-175

Punithalingam, E. (1979). Sphaeropsidales in cultures from human. Nova Hedwigia 31:119-158

Schneider, R. (1979). Die Gattung Pyrenochaeta De Notaris. Mitt.biol.Bd. Anst. Ld-u. Forstw.189:1-73
Sutton, B.C. (1980). The Coelomycetes. Fungi imperfecti with pycnidia, acervuli and stromata. CMI. Kew.

Sutton, D.A. (1999). Coelomycetous fungi in human disease. A Review: Clinical entities, pathogenesis, identification and therapy. Rev. Iberoam. Micol. 16:171-179

Untereiner, W. A. (1997). Taxonomy of selected members of the ascomycete genus Capronia with notes on anamorph-teleomorph connections. Mycologia 89:120-131 
